\title{
INEQUALITIES FOR A POLYNOMIAL AND ITS DERIVATIVE
}

\author{
A. AZIZ AND W. M. SHAH
}

Abstract. In this paper we consider a class of polynomials $P(z)=a_{0}+\sum_{j=\mu}^{n} a_{j} z^{j}, 1 \leqslant \mu \leqslant n$, not vanishing in the disk $|z|<K$. For $K \geqslant 1$, we investigate the dependence of $\max _{|z|=1} \mid P(R z)-$ $P(z) \mid$ on $\max _{|z|=1}|P(z)|$ and for $K>0$ we estimate $\max _{|z|=R}\left|P^{\prime}(z)\right|$ in terms of $\max _{|z|=r}|P(z)|$, $0 \leqslant r \leqslant R \leqslant K$. Our results not only generalize some known polynomial inequalities, but olso a variety of interesting results can be deduced from these by a fairly uniform procedure. We also obtain a generalization of a Theorem of Paul Turan.

Mathematics subject classification (2000): 30A10, 30C10, 30D15.

Key words and phrases: Polynomials, inequalities.

\section{REFERENCES}

[1] N. C. AnKeny and T. J. Rivlin, On a theorem of S. Bernstein, Pacific J. Math. 5 (1955), 849-852.

[2] A. AzIz, Inequality for the derivative of a polynomial, Proc. Amer. Math. Soc. 89 (1983), 259-266.

[3] A. AzIZ AND Q. M. Dawood, Inequalities for a polynomial and its deivative, J. Approx. Theory. 54 (1988), 306-313.

[4] A. AZIZ AND N. A. RATHER, New $L^{q}$ inequalities for polynomials, Mathematical Inequalities and Applications (1999), 177-191.

[5] A. AZIZ AND W. M. SHAH, $L^{q}$ inequlities for polynomials with restricted zeros, Glasnik Matematički 32 (1997), 249-258.

[6] S. BERNSTEIN, Lecons Sur Les Proprie'le's extre'males et la meilleure approximation des fonctions analytiques d'une fonctions reele, Paris, 1926.

77] T. N. Chan AND M. A. MaLiK, On Erdös-Lax theorem, Proc. Indian Acad. Sci. 137 (1969), 501-517.

[8] B. DatT, Ph. D. Thesis, submitted to the Indian Institute of Technology, Delhi, 1976.

[9] K. K. Dewan, Ph. D. Thesis, submitted to the Indian Institute of Technology, Delhi, 1980.

[10] K. K. DEWAN AND M. BIDKHAM, Inequalities for a polynomial and its derivative, J. Math. Anal. Appl. 166 (1992), 319-324.

[11] C. FRAPPIER, Q. I. ReHMAN AND S. T. RUSCHEWEYH, New inequalities for polynomials, Trans. Amer. Math. Soc. 288 (1985), 69-99.

[12] N. K. GOVIL, Q. I. RAHMAN AND G. SCHMEISSER, On the derivative of a polynomial, Illinois J. Math. 23 (1979), 319-329.

[13] P. D. LAX, Proof of a conjecture of P. Erdös on the derivative of polynomial, Bull. Amer. Math. Soc. (N. S.) 50 (1944), 509-513.

[14] M. A. MALIK, On the derivative of a polynomial, J. London Math. Soc. 1 (1969), 57-60.

[15] G. V. Milovanović, D. S. Mitrinović AND TH. M. RAssias, Topics in polynomials, Extremal Problems, Inequalities, zeros, World Scientific, Singapore, 1994.

[16] M. S. Pukhta, Ph. D. thesis, submitted to the Jamia Millia Islamia, New Delhi, 1995.

[17] M. A. QAZI, On the maximum modulus of polynomials, Proc. Amer. Math. Soc. 115 (1992), 337-343.

[18] M. RIEZE, Über einen Satz der Hern Serge Bernstein, Acta Math. 40 (1918), 337-347.

[19] P. TURA'N, Über die ablaeitung von polynomen, Compositio Math. Soc. 25 (1993), 49-54. 